\title{
Linear Regression Relationship between Lychee Juice Content and Buffering Capacity
}

\author{
Jijun Wu ${ }^{1,2 *}$, Yujuan Xu1 ${ }^{1}$, Gengsheng Xiao', Yuanshan Yu${ }^{1}$, Jing Wen ${ }^{1}$ \\ ${ }^{1}$ Sericultural \& Agri-Food Research Institute, Guangdong Academy of Agricultural Sciences/Key Laboratory of \\ Functional Foods, Ministry of Agriculture/Guangdong Key Laboratory of Agricultural Products Processing, \\ Guangzhou, China \\ ${ }^{2}$ Guangdong Bosun Health Food Co. Ltd., Guangzhou, China \\ Email: "wujijun@126.com
}

Received 18 January 2016; accepted 19 April 2016; published 22 April 2016

Copyright (C) 2016 by authors and Scientific Research Publishing Inc.

This work is licensed under the Creative Commons Attribution International License (CC BY). http://creativecommons.org/licenses/by/4.0/

(c) () Open Access

\begin{abstract}
Juice drinks are an important commercialization alternative for lychee, a tropical and subtropical fruit. Although the lychee juice content is important when assessing the quality of a drink, there are no published methods to determine it, particularly simple ones for the routine inspection of juice drinks. Lychee juice drinks contain ingredients with buffering capacity including proteins and ions such as phosphate, citrate, lactate, carbonate, acetate and propionate. The relationship between their buffering capacity and lychee juice content was studied. Citric acid was added to pure lychee dilutions in distilled water containing $100 \%, 90 \%, 80 \%, 70 \%, 60 \%, 50 \%, 40 \%, 30 \%$, $\mathbf{2 0 \%}$ and $\mathbf{1 0 \%}$ lychee juice. The $\mathrm{pH}$ of the dilutions was measured to obtain a linear model for the molar $\mathrm{H}^{+}$concentration as a function of the added citric acid $(\mathrm{g} / \mathrm{L})$ amount $\mathrm{LC}=(\mathrm{BC}-494.2) / 12,031$, where LC was the lychee juice content and BC was defined as the juice buffering coefficient.
\end{abstract}

\section{Keywords}

Lychee Juice, Buffering Capacity, Buffering Coefficient

\section{Introduction}

Juice drinks are an important commercialization alternative for lychee, a tropical and subtropical fruit with high consumer acceptance and high nutritional value [1]. Although the lychee juice content is important in the assessment of the quality of a juice drink, there are no published methods to determine it. The RSK-values system was officially established by the Federal Republic of Germany in 1980 to measure the juice content in drinks. Numerous methods have been developed to detect juice content in drinks based on measuring characteristic ${ }^{*}$ Corresponding author.

How to cite this paper: Wu, J.J., Xu, Y.J., Xiao, G.S., Yu, Y.S. and Wen, J. (2016) Linear Regression Relationship between Lychee Juice Content and Buffering Capacity. Food and Nutrition Sciences, 7, 236-239. 
components found in the juice. Beatriz et al. published phenol profiles of 58 citrus varieties in Spain in a study aimed at developing a database to be used in the identification of adulterated drinks but were not appropriate for the routine determination of juice content [2].

Ehling and Cole used the pomegranate juice organic acids spectrum to identify adulteration [3]. With the same objective, Obón et al. identified the types and amounts of anthocyanins in red fruit juice [4]. In Slovenia and Cyprus, Ogrinc et al. used nuclear magnetic resonance (NMR) spectroscopy to determine the ${ }^{13} \mathrm{C} /{ }^{12} \mathrm{C},{ }^{2} \mathrm{H}^{11} \mathrm{H}$ and ${ }^{18} \mathrm{O} /{ }^{16} \mathrm{O}$ ratios to distinguish juice drinks in these markets prepared from concentrated or fresh juice [5]. Juraj \& Milan measured capillary isotachophoresis anion profiles in orange juice to identify adulteration [6]. Evelyne \& Freddy used ${ }^{1} \mathrm{H}$-NMR spectroscopy to explore the difference between orange juice and wide leather citrus juice [7]. Faria et al. evaluated the effectiveness of High Resolution Melting Analysis for species discrimination with the DNA fragment trnL [8]. Kurz et al. evaluated the reliability of FT-NIR spectroscopy to determine the real juice contents in juice products including apricot juice, peach juice and pumpkin juice [9]. IIkay determinated chemical composition, antioxidant activity and anthocyanin profiles of purple mulberry (Morus rubra) fruits. The results can be used to estimate the muluberry juice content [10].

As there is a correlation between lychee juice content and buffering capacity, when a given amount of citric acid is added into a lychee juice drink, its $\mathrm{pH}$ will change more if the lychee juice content is lower. This observation was used to develop a simple and rapid method to detect lychee juice content in juice drinks.

\section{Materials and Methods}

\subsection{Lychee Juice}

Fresh lychee juice (Litchi chinensis Sonn.) was obtained from CongHua Shunchangyuan Green Food Co. Ltd., Guangzhou, China, was produced by washing, peeling, pitting and pressing the fruit and finally by filtration through a 60 -mesh sieve. Ten lots of commercial juice were diluted with distilled water to prepare in a $250 \mathrm{~mL}$ beaker, $50 \mathrm{~mL}$ lychee juice drinks containing 100\%, 90\%, 80\%, 70\%, 60\%, 50, 40\%, 30\%, 20\% and 10\% pure lychee juice.

\subsection{Determination of the Buffering Capacity of Juice Drinks}

Under constant agitation of the $10 \%$ - 100\% lychee juice drinks using a magnetic stirring bar, up to $1.6 \mathrm{~mL}$ of

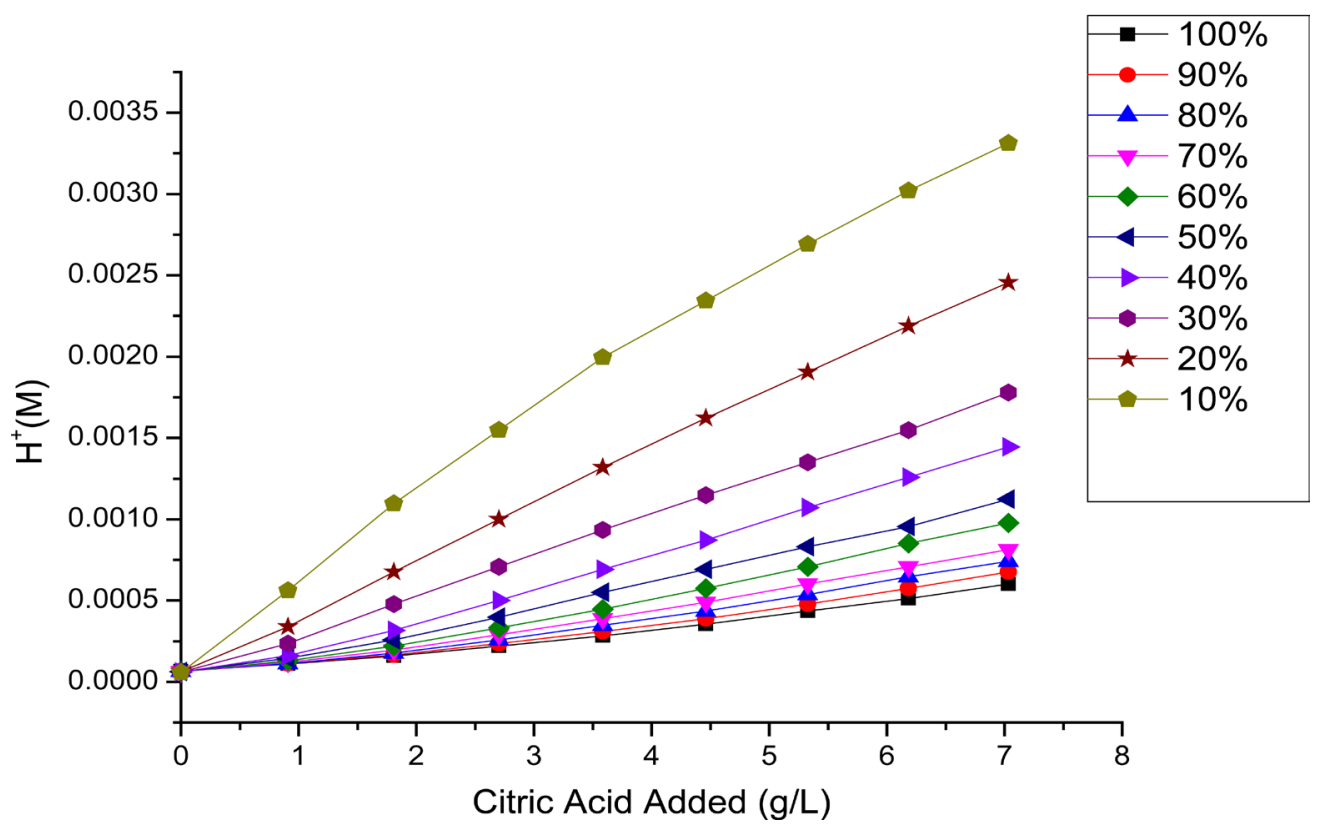

Figure 1. Effect on the molar $\mathrm{H}^{+}$concentration when adding at $0.2 \mathrm{~mL}$ intervals up to $1.6 \mathrm{~mL}$ of monohydrate citric acid (25 $\mathrm{g} / 100 \mathrm{~mL}$ water) acid into $50 \mathrm{~mL}$ of drinks containing $10 \%-100 \%$ lychee juice to define the drink buffering capacity (BC) as the linear correlation slope. 
Table 1. Determination of the drink buffering capacity (BC) as the slope of the linear correlation between the molar $\mathrm{H}^{+}$concentration values (Y) measured after adding up to $1.6 \mathrm{~mL}$ of monohydrate citric acid (25 $\mathrm{g} / 100 \mathrm{~mL}$ water) at $0.2 \mathrm{~mL}$ intervals (X) into $50 \mathrm{~mL}$ of different lychee juice content (LC) drinks.

\begin{tabular}{cccc}
\hline LC & Linear regression & $\mathrm{R}^{2}$ & $\mathrm{BC}$ \\
\hline $100 \%$ & $\mathrm{Y}=12282 \mathrm{X}-0.3692$ & 0.9857 & 12,282 \\
$90 \%$ & $\mathrm{Y}=11273 \mathrm{X}-0.2092$ & 0.9838 & 11,273 \\
$80 \%$ & $\mathrm{Y}=10021 \mathrm{X}-0.1383$ & 0.9877 & 10,021 \\
$70 \%$ & $\mathrm{Y}=9060.4 \mathrm{X}-0.1366$ & 0.9917 & 9060.4 \\
$60 \%$ & $\mathrm{Y}=7409.5 \mathrm{X}+0.0178$ & 0.9895 & 7409.5 \\
$50 \%$ & $\mathrm{Y}=6400.1 \mathrm{X}+0.0212$ & 0.9934 & 6470.0 \\
$40 \%$ & $\mathrm{Y}=4901.3 \mathrm{X}+0.0833$ & 0.9946 & 4901.3 \\
$30 \%$ & $\mathrm{Y}=4056.0 \mathrm{X}-0.1560$ & 0.9994 & 4056.0 \\
$20 \%$ & $\mathrm{Y}=2896.8 \mathrm{X}-0.1657$ & 0.9994 & 2896.8 \\
$10 \%$ & $\mathrm{Y}=2144.1 \mathrm{X}-0.4046$ & 0.9916 & 2144.1 \\
\hline
\end{tabular}

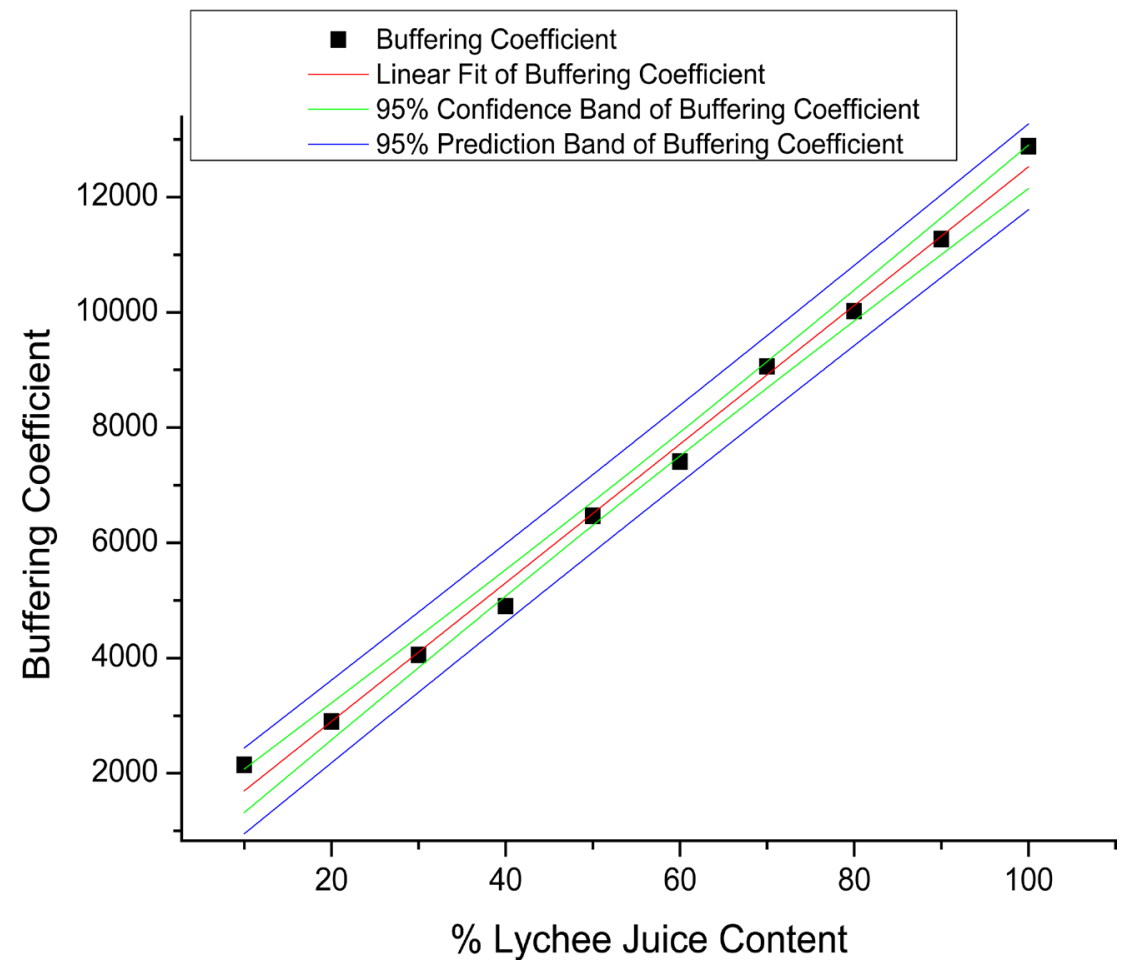

Figure 2. Effect of the lychee juice content (LC) on the buffering coefficient (BC) of the juice drink defining a method to identify the juice content in commercial products.

monohydrate citric acid $(25 \mathrm{~g} / 100 \mathrm{~mL}$ water) were added into each dilution. After the addition of every $0.2 \mathrm{~mL}$ citric acid, the $\mathrm{pH}$ of the lychee juice solutions was measured (Type PB-20, Sartorius, Germany) and recorded. The monohydrate citric acid used was of analytical reagent quality.

The molar $\mathrm{H}^{+}$concentration $\left(=10^{-\mathrm{pH}}\right)$ was linearly correlated to the amount of citric acid ( $\mathrm{g} / \mathrm{L}$ drink) added to each of the $10 \%-100 \%$ lychee juice drinks. The slope for each drink was defined as its buffering coefficient (BC) and correlated to its lychee juice content. Origin 8.6 was used for statistical analysis and graphics software

\section{Results and Discussion}

The effect on the molar $\mathrm{H}^{+}$concentration when adding up to $1.6 \mathrm{~mL}$ of monohydrate citric acid $(25 \mathrm{~g} / 100 \mathrm{~mL}$ water) acid to $50 \mathrm{~mL}$ of ten drinks containing $10 \%-100 \%$ lychee juice is shown in Figure 1. Linear regression equations of 10 lychee juice concentrations drinks are shown in Table 1 indicate the $\mathrm{BC}$ values obtained which were then correlated with the lychee juice content (LC) (Figure 2) leading to the following expressions: 


$$
\begin{gathered}
B C=12031 \times L C+494.2 \\
L C=\frac{B C-494.2}{12031}
\end{gathered}
$$

\section{Conclusion}

A linear correlation between the buffering coefficient and the juice content in lychee juice drinks was determined experimentally to develop a simple and rapid method of analysis. The juice content in lychee juice drink can be estimated by measuring the buffering coefficient. However, the buffering capacity of lychee juice may be influenced by several factors, such as proteins, phosphate, citrate, lactate, carbonate, acetate and propionate ions which may reflect not only lychee juice content but other factors not included in this study.

\section{Acknowledgements}

This work was funded by Guangdong Project (2015A030312001), the Project of the National Key Technology Research and Development Program for the 12th Five-year Plan (2012BAD31B03), Guangzhou project (2014Y200099), and Guangdong Maoming Project (2012A012012001).

\section{References}

[1] Jiang, Y., Duan, X., Joyce, D., Zhang, Z. and Li, J. (2004) Advances in Understanding of Enzymatic Browning in Harvested Litchi Fruit. Food Chemistry, 88, 443-446. http://dx.doi.org/10.1016/j.foodchem.2004.02.004

[2] Beatriz, A.G., Sergio, G.L., Luis, A., Gallo, B. and Vicente, F. (2012) On Line Characterization of 58 Phenolic Compounds in Citrus Fruit Juices from Spanish Cultivars by High-Performance Liquid Chromatography with PhotodiodeArray Detection Coupled to Electrospray Ionization Triple Quadrupole Mass Spectrometry. Talanta, 99, $213-224$. http://dx.doi.org/10.1016/j.talanta.2012.05.042

[3] Ehling, S. and Cole, S. (2011) Analysis of Organic Acids in Fruit Juices by Liquid Chromatography-Mass Spectrometry: An Enhanced Tool for Authenticity Testing. Journal of Agricultural and Food Chemistry, 59, 2229-2234. http://dx.doi.org/10.1021/jf104527e

[4] Obón, J.M., Díaz-García, M.C. and Castellar, M.R. (2011) Red Fruit Juice Quality and Authenticity Control by HPLC. Journal of Food Composition and Analysis, 24, 760-771. http://dx.doi.org/10.1016/j.jfca.2011.03.012

[5] Ogrinc, N., Bat, K., Kosir, I., Golob, T. and Kokkinofta, R. (2009) Characterization of Commercial Slovenian and Cypriot Fruit Juices Using Stable Isotopes. Journal of Agricultural and Food Chemistry, 57, 6764-6769. http://dx.doi.org/10.1021/jf9009944

[6] Jezek, J. and Suhaj, M. (2001) Application of Capillary Isotachophoresis for Fruit Juice Authentication. Journal of Chromatography, 916, 185-189. http://dx.doi.org/10.1016/S0021-9673(00)01078-5

[7] Vigneau, E. and Thomas, F. (2012) Model Calibration and Feature Selection for Orange Juice Authentication by ${ }^{1} \mathrm{H}$ NMR Spectroscopy. Chemometrics and Intelligent Laboratory Systems, 117, 22-30. http://dx.doi.org/10.1016/j.chemolab.2011.05.006

[8] Faria, M.A., Magalhães, A., Nunes, M.E. and Oliveira, M.B.P.P. (2013) High Resolution Melting of trnL Amplicons in Fruit Juices Authentication. Food Control, 33, 136-141. http://dx.doi.org/10.1016/j.foodcont.2013.02.020

[9] Kurz, C., Leitenberger, M., Carle, R. and Schieber, A. (2010) Evaluation of Fruit Authenticity and Determination of the Fruit Content of Fruit Products Using FT-NIR Spectroscopy of Cell Wall Components. Food Chemistry, 119, 806812. http://dx.doi.org/10.1016/j.foodchem.2009.07.028

[10] Koca, I., Ustun, N.S., Koca, A.F. and Karadeniz, B. (2008) Chemical Composition, Antioxidant Activity and Anthocyanin Profiles of Purple Mulberry (Morus rubra) Fruits. Journal of Food Agriculture and Environment, 6, 39-42. 